\title{
HUBUNGAN STATUS GIZI DENGAN KEJADIAN DISMENOREA PADA REMAJA PUTRI DI SMPN 2 TANJUNG TIMUR KEC. STM HULU KABUPATEN DELI SERDANG
}

\author{
Yulina Dwi Hastuty \\ Jurusan Kebidanan Poltekkes Kemenkes Medan
}

\begin{abstract}
Abstrak
Nyeri haid dalam istilah medis disebut dismenore, sebenarnya merupakan suatu kondisi yang umum dialami oleh kaum hawa yang sudah mendapatkan menstruasi. Menurut data WHO, didapatkan kejadian sebesar 1.769.425 jiwa (90\%) wanita yang mengalami dismenore adi dunia dengan $10-15 \%$ mengalami dismenorea berat. Angka dismenore di dunia sangat besar, rata- rata lebih dari $50 \%$ perempuan di setiap negara mengalami dismenorea. Dismenorea adalah nyeri kram yang sering diikuti dengan nyeri punggung bawah, mual, muntah, sakit kepala dan diare nyeri yang terjadi pada dismenorea dapat memaksa wanita untuk istirahat atau berakibat pada menurunnya kinerja dan berkurangnya aktifitas sehari-hari. Tujuan penelitian untuk mengetahui hubungan status gizi dengan kejadian dismenorea pada remaja putri di SMPN 2 Tanjung Timur Kec. STM Hulu Kabupaten Deli Serdang. Design penelitian yang digunakan adalah survey analitik dengan menggunakan pendekatan Cross Sectional. Populasi dan sampel penelitian ini adalah seluruh siswa kelas VII-IX SMPN 2 Tanjung Timur sebanyak 70 orang. Data diambil dengan menggunakan kuesioner kemudian di analisa dengan menggunakan analisa chi square dengan tingkat kepercayaan $\alpha=$ 0,05 . Hasil penelitian menunjukkan ada hubungan antara status gizi dengan kejadian dismenore dimana nilai $\mathrm{P}$ value sebesar 0,015 .
\end{abstract}

Kata kunci : Status Gizi, Kejadian Dismenorea, Menstruasi

\section{PENDAHULUAN}

Masa remaja merupakan salah satu tahap dalam kehidupan manusia yang sering disebut sebaga masa pubertas yaitu masa peralihan dari anak-anak ke masa dewasa. Pada tahap ini remaja akan mengalami suatu perubahan fisik, emosional dan social sebagai cirri dalam masa pubertas, dan dari berbagai ciri pubertas tersebut.

Menurut WHO (World Health Organization) usia remaja merupakan suatu periode transisi dalam upaya menemukan jati diri dan kedewasaan biologis serta psikologi. Usia tersebut merupakan periode kritis sehingga perlu dibina dan dibimbing dengan benar. Remaja yang dimaksud adalah mereka yang berusia antara $10-19$ tahun. Menurut hasil Survey Demografi dan Kesehatan Indonesia (SDKI) tahun 2011 jumlah penduduk usia 10 19 tahun mencakup 22,9\% dari jumlah penduduk Indonesia (Dinkes, 2012).

Menurut data WHO, didapatkan kejadian sebesar 1.769.425 jiwa (90\%) wanita yang mengalami dismenorea dengan 10 - 15\% mengalami dismenorea berat. Menurut WHO angka dismenore di dunia sangat besar, rata-rata lebih dari $50 \%$ perempuan di setiap negara mengalami dismenore. Angka kejadian di Swedia sekitar 72\%, di Amerika Serikat diperkirakan hampir 90\% wanita mengalami dismenore, dan $10-15 \%$ diantaranya mengalami dismenore berat, yang menyebabkan mereka tidak mampu melakukan kegiatan apapun (Ningsih, 2011). Menurut Hasil Riskesdas di Indonesia responden yang sudah mengalami haid, rata-rata usia menarche adalah 13 tahun $(20,0 \%)$ dengan kejadian lebih awal pada usia kurang dari 9 tahun dan ada yang lebih lambat sampai 20 tahun serta 7,9\% tidak menjawab/lupa. Terdapat 7,8\% yang melaporkan belum haid. Secara nasional rata-rata usia menarche 13-14 tahun terjadi pada 37,5\% anak Indonesia (Riset Kesehatan Dasar, 2010)

Menurut penelitian yang dilakukan di Medan oleh Purba (2013) penderita dismenore di SMK Negeri 10 Medan tahun 2013 sebanyak 81,30\%. Nyeri haid atau dismenorea merupakan masalah umum yang sering dikeluhkan oleh wanita yang mengalami menstruasi. Hal ini merupakan permasalahan ginekologikal utama yang paling sering dikeluhkan. Faktor terjadinya adalah keadaan psikis dan fisik seperti stres, shock, penyempitan pembuluh darah, kurang darah, dan kondisi tubuh yang menurun (Diyan, 2013).

Menstruasi pertama kali biasanya dialami oleh perempuan sekitar usia 10 tahun, namun bisa juga lebih dini atau lebih lambat. Menstruasi merupakan hal yang menandakan bahwa seorang perempuan tersebut sehat serta sistem reproduksinya bekerja dengan normal. Sehingga terjadinya menstruasi sangatlah penting, khususnya bagi kesehatan organ reproduksi seorang 
perempuan (Purwanti (2014). Nyeri haid dalam istilah medis disebut dismenore, sebenarnya merupakan suatu kondisi yang umum dialami oleh kaum hawa yang sudah mendapatkan menstruasi (Purwanti,2014).

Salah satu faktor yang mempengaruhi faktor terjadinya Dismenorea adalah yang berhubungan dengan kejadian Dismenorea adalah Status gizi. Status gizi remaja wanita sangat mempengaruhi terjadinya menstruasi, adanya keluhan-keluhan selama menstruasi maupun lamanya hari menstruasi. Tetapi pada beberapa remaja keluhan-keluhan tersebut tidak dirasakan, hal ini dipengaruhi oleh nutrisi yang adekuat yang biasa dikonsumsi, selain olahraga yang teratur. Status gizi merupakan salah satu faktor resiko terjadinya dismenore primer, status gizi yang rendah (underweight) dapat diakibatkan karena asupan makanan yang kurang, termasuk zat besi yang dapat menimbulkan anemia (Rahmadhayanti, 2016).

Berdasarkan hasil survei pendahuluan pada tanggal 16 Mei 2017 yang dilakukan terhadap 10 siswi di Sekolah SMPN 2 Tanjung Timur, didapatkan 7 orang yang mengalami Dismenorea saat menstruasi. Nyeri haid terjadi pada hari pertama dan kedua menstruasi. Dari 7 orang yang mengalami Dismenorea, terdapat 2 orang sering meninggalkan pelajaran karena nyeri haid yang tidak tertahankan.

Dari hasil survei pendahuluan yang dilakukan di SMPN 2 Tanjung Timur terdapat beberapa orang yang mengalami dismenorea. Berdasarkan data di atas, perlu dilakukan penelitian untuk mengetahui hubungan status gizi dengan kejadian dismenorea pada remaja putri di SMPN 2 Tanjung Timur.

Berdasarkan hal-hal tersebut di atas, maka peneliti tertarik untuk mengetahui hubungan status gizi dengan kejadian dismenorea pada remaja putri di SMPN 2 Tanjung Timur Kec. STM Hulu Kabupaten Deli Serdang

\section{Rumusan Masalah}

Berdasarkan latar belakang tersebut yang menjadi perumusan masalah adalah "Adakah hubungan status gizi dengan kejadian dismenorea pada remaja putri di SMPN 2 Tanjung Timur Kec. STM Hulu Kabupaten Deli Serdang"

\section{Tujuan Penelitian}

Tujuan dari penelitian ini untuk mengetahui hubungan status gizi dengan kejadian dismenorea pada remaja putri di SMPN 2 Tanjung Timur Kec. STM Hulu Kabupaten Deli Serdang.

\section{METODE PENELITIAN}

\section{Jenis Penelitian}

Jenis penelitian yang di gunakan adalah penelitian yang bersifat Analitik dengan pendekatan Cross Sectional.

\section{Lokasi dan Waktu penelitian}

Penelitian dilakukan di SMPN 2 Tanjung Timur. Kec STM. Hulu.Kabupaten Deli Serdang pada bulan Agustus 2017.

\section{Populasi dan Sampel}

Populasi penelitian adalah seluruh siswi kelas VIIIX di SMPN 2 Tanjung Timur Kabupaten Deli Serdang tahun 2017 yang sudah mendapatkan haid sebanyak 70 orang dan seluruhnya dijadikan sampel.

\section{Metode Pengumpulan Data}

Data yang digunakan adalah data primer yang diambil langsung oleh peneliti di SMPN 2 Tanjung Timur Kabupaten Deli Serdang, dengan menggunakan instrument penelitian berupa kuisioner yang diberikan kepada responden.

\section{Pengolahan dan Analisis Data}

Data yang diperoleh di edit dan ditabulasi untuk selanjutnya dianalisis secara univariat dan bivariat. Pengujian data dilakukan dengan menggunakan uji statistic Chi Square dengan nilai kemaknaan $(\alpha=0.05)$.

\section{HASIL PENELITIAN}

\section{Analisa Univariat}

Deskripsi responden dalam penelitian ini menggambarkan karakteristik responden menurut umur, Berat Badan (BB), Tinggi Badan (TB), Indek Masa Tubuh (IMT) dan Kejadian Dismenore Remaja Putri di SMPN 2 Tanjung Timur Kec. STM Hulu Kabupaten Deli Serdang Tahun 2017.

\section{Tabel 1}

Distribusi Responden Berdasarkan Umur, Berat Badan, dan Tinggi Badan ( $N=70)$

\begin{tabular}{ccc}
\hline Kelompok Umur & $\mathbf{F}$ & \% \\
\hline$<12$ tahun & 5 & 7.1 \\
$12-14$ tahun & 63 & 90.0 \\
$>14$ tahun & 2 & 2.9 \\
\hline Total & 70 & 100.0 \\
\hline Berat Badan $(\mathbf{B B})$ & $\mathbf{F}$ & $\boldsymbol{\%}$ \\
\hline$<40 \mathrm{~kg}$ & 31 & 44.3 \\
$40-45 \mathrm{~kg}$ & 30 & 42.9 \\
$>45 \mathrm{~kg}$ & 9 & 12.9 \\
\hline Total & 70 & 100.0 \\
\hline Tinggi Badan & $\mathbf{F}$ & $\boldsymbol{\%}$ \\
\hline$<145 \mathrm{~cm}$ & 7 & 10.0 \\
$145-150 \mathrm{~cm}$ & 20 & 28.6 \\
$>150 \mathrm{~cm}$ & 43 & 61.4 \\
\hline Total & 70 & 100.0 \\
\hline
\end{tabular}

Berdasarkan tabel di atas diperoleh gambaran bahwa umur responden terbanyak adalah kelompok umur 12-14 tahun yaitu 63 orang (90\%), sedangkan Berat badan (BB) dari responden terbanyak adalah 40-45 kg sebanyak 30 orang $(42,9 \%)$. Berdasarkan tabel di atas juga diperoleh gambaran bahwa responden yang memiliki tinggi badan terbanyak adalah tinggi badan $>150 \mathrm{~cm}$ yaitu 43 orang $(61,4 \%)$. 
Tabel 2

Status Gizi Responden (N=70)

\begin{tabular}{ccc}
\hline Status Gizi & f & \% \\
\hline Kurus & 38 & 54.28 \\
Normal & 27 & 38.57 \\
Gemuk & 5 & 7.15 \\
\hline Total & 70 & 100.0 \\
\hline
\end{tabular}

Berdasarkan tabel di atas diperoleh gambaran responden dalam hal status gizi dimana Responden terbanyak dalam kategori Kurus ada 38 orang $(54,28 \%)$ sementara ada 5 orang responden $(7,15 \%)$ memiliki status gizi kategori gemuk.

\section{Tabel 3}

Kejadian Dismenore pada responden $(\mathbf{N}=70)$

\begin{tabular}{ccc}
\hline Kejadian Dismenore & f & \% \\
\hline Tidak terjadi Dismenore & 12 & 17.15 \\
Terjadi dismenore & 58 & 82.85 \\
\hline Total & 70 & 100.0 \\
\hline
\end{tabular}

Berdasarkan tabel di atas diperoleh gambaran bahwa Kejadian Dismenore paling banyak terjadi dismenore pada responden sebanyak 58 responden $(82,85 \%)$.

\section{A.2 Analisa Bivariat}

Tabel 4

Hubungan Status Gizi dengan Kejadian Dismenore $(\mathbf{N}=\mathbf{7 0})$

\begin{tabular}{|c|c|c|c|c|c|c|c|c|c|}
\hline \multirow{2}{*}{$\begin{array}{c}\text { Kejadian } \\
\text { dismenorea }\end{array}$} & \multicolumn{7}{|c|}{ Status Gizi } & $\begin{array}{c}\text { P } \\
\text { value }\end{array}$ \\
\cline { 2 - 10 } & Gemuk & \multicolumn{2}{|c|}{ Normal } & \multicolumn{2}{|c|}{ Kurus } & \multicolumn{2}{|c|}{ Total } & \\
\cline { 2 - 10 } & $\mathrm{f}$ & $\%$ & $\mathrm{f}$ & $\%$ & $\mathrm{f}$ & $\%$ & $\mathrm{f}$ & $\%$ & \\
\hline Terjadi & 4 & 6,89 & 22 & 37,93 & 32 & $\begin{array}{c}55,1 \\
7\end{array}$ & 58 & 82,85 & \multirow{2}{*}{0.015} \\
\hline $\begin{array}{c}\text { Tidak } \\
\text { terjadi }\end{array}$ & 6 & 50 & 5 & 41,66 & 1 & 8,33 & 12 & 17,15 & \\
\hline Total & 10 & 14,2 & 27 & 38,6 & 33 & 47,2 & 70 & 100 & \\
\hline
\end{tabular}

Berdasarkan tabel di atas diperoleh gambaran bahwa dari 58 responden $(82,85 \%)$ yang mengalami kejadian dismenorea mayoritas dengan status gizi kurus sebanyak 32 responden $(55,17 \%)$ sedangkan responden dengan status gizi gemuk mayoritas tidak mengalami dismenore. Nilai $P$ value yang dihasilkan sebesar $0,015<$ 0,05 sehingga dinyatakan Status gizi dengan kejadian dismenore berhubungan nyata

\section{PEMBAHASAN}

\section{Status Gizi}

Berdasarkan hasil analisa diperoleh gambaran bahwa gambaran status gizi responden terbanyak adalah kategori Kurus ada 38 orang (54,28\%) sementara ada 5 orang responden $(7,15 \%)$ memiliki status gizi kategori gemuk.

Status gizi remaja putri di SMPN 2 Tanjung Timur Kec. STM Hulu Kab.Deli Serdang mayoritas dalam kategori kurus. Hal ini menyebabkan remaja putri mayoritas mengalami dismenore pada saat menstruasi.

Status gizi merupakan tanda-tanda penampilan seseorang akibat keseimbangan antara pemasukan dan pengeluaran zat gizi yang berasal dari pangan yang dikonsumsi pada suatu saat berdasarkan pada kategori dan indikator yang digunakan. Seseorang dikatakan memiliki gizi Kurus apabila IMT $\leq 18,5$. Normal apabila IMT $>$ 18,5 - 25,0 dan Gemuk jika IMT > 25.

Status gizi adalah keadaan tubuh akibat mengkonsumsi makanan dan penggunaan zat-zat gizi. Status gizi dibedakan menjadi tiga yaitu status gizi kurang, status gizi baik, dan status gizi lebih. Penentuan status gizi remaja dapat dilakukan dengan beberapa cara salah satunya dengan menggunakan Indeks Masa Tubuh (IMT). Pengukuran ini cocok untuk remaja karena remaja masih dalam masa pertumbuhan (Almatsier, 2010).

Perlunya pemenuhan zat gizi pada usia remaja, terutama remaja putri berhubungan dengan perannya dimasa yang akan datang sebagai calon ibu. Kondisi seseorang pada masa dewasa ditentukan oleh keadaan pada masa remaja. Pada usia remaja keadaan gizi dan kesehatan harus diperhatikan karena remaja putri menjadi wanita dewasa yang melahirkan generasi berikutnya. Masalah gizi yang paling sering terjadi pada remaja adalah kurangnya asupan gizi yang mengakibatkan kurang gizi yaitu terlalu kurus dan dapat terkena anemia karena kekurangan zat besi. Selain itu masalah gizi yang sering muncul adalah kelebihan asupan gizi yang dapat menyebabkan obesitas (Waryana, 2010).

\section{Kejadian Dismenorea}

Berdasarkan hasil analisa diperoleh gambaran bahwa kejadian dismenore paling banyak dialami 58 responden $(82,85 \%)$ dan 12 orang responden $(17,15 \%)$ tidak mengalami kejadian dismenore. Seseorang mengalami dismenore jika Responden tersebut mengalami nyeri saat menstruasi.

Penelitian di Jakarta tahun 2004 menemukan bahwa 83,5\% mahasiswi mengalami dismenore. Pada penelitian yang sama di Palembang angka kejadian dismenore pada siswi SMP Negeri 3 Palembang adalah $58,2 \%$ dan SMP negeri 28 palembang adalah $66,3 \%$, dismenore dapat menyebabkan seseorang menjadi lemas tidak bertenaga, sehingga berdampak negatif pada kegiatannya sehari-hari dan secara psikologi akan sangat mengganggu, bahkan menjadi salah satu alasan tersering wanita tidak melakukan aktifitas (sekolah, kerja, dan lainlain). Dismenore cenderung terjadi lebih sering dan lebih hebat, pada gadis remaja yang mengalami kegelisahan, ketegangan dan kecemasan. Rasa nyeri dismenore memberikan dampak negatif pada kualitas hidup penderita serta status ekonomi diri sendiri penderita dan keluarganya, terganggu aktivitas sehari-hari, ketinggalan mata pelajaran atau kuliah, endometrosis, gangguan psikologis.

Dismenore biasanya baru timbul 2 atau 3 tahun sesudah menarche atau pertama kali menstruasi. Dismenore ada yang ringan dan ada yang samar samar, ada pula yang berat bahkan beberapa wanita telah pingsan dan ada yang harus ke dokter karena 
nyeri yang dialaminya mengganggu aktivitasnya (Asrinah, 2011 dalam Mulyani, 2012). Ternyata hampir $30 \%$ wanita yang mengeluhkan dismenore adalah anak gadis dari ibu yang dulunya dismenore, serta sebanyak $7 \%$ saudara wanita yang mengalami dismenore juga mengeluhkan hal yang sama, meskipun ibu mereka dulunya tidak mengeluhkan dismenore (Yatim, 2001 dalam Mulyani, 2012). Angka kejadian dismenore di dunia sangat besar. Rata-rata lebih dari $50 \%$ wanita di setiap negara mengalami dismenore. Di Amerika angka persentasinya sekitar $60 \%$ dan di Swedia sekitar $72 \%$. Sementara di Indonesia angkanya diperkirakan 55\% wanita produktif yang terganggu oleh dismenore.

Karena penderita terbanyak adalah pada wanita usia produktif, akibatnya dismenorea juga menyebabkan ketidakhadiran saat bekerja dan sekolah, sebanyak 13-51\% wanita telah absen sekali dan 5-14\% berulang kali absen (Anurogo, 2008 dalam Yuniarti, Rejo, \& Handayani, 2012). Penelitian di Amerika Serikat menyebutkan bahwa dismenore dialami oleh 30-50\% wanita usia reproduksi dan 10-15\% diantaranya kehilangan kesempatan kerja, mengganggu kegiatan belajar di sekolah dan kehidupan keluarga (Paramita, 2010 dalam Purba, Rompas \& Karundeng, 2014).

\section{Hubungan Status Gizi dengan Kejadian Dismenorea}

Berdasarkan hasil analisa diperoleh gambaran bahwa dari 58 responden $(82,85 \%)$ yang mengalami kejadian dismenorea terdapat 4 responden $(6,89 \%)$ yang memiliki Status gizi gemuk, terdapat 22 responden $(37,93 \%)$ yang memiliki status gizi yang normal, 32 responden $(55,17 \%)$ yang memliki status gizi kurus.

Berdasarkan hasil analisa diperoleh gambaran bahwa dari 12 responden $(17,15 \%)$ yang tidak mengalami kejadian dismenorea terdapat 6 responden yang memiliki status gizi gemuk, terdapat 5 orang $(41,66 \%)$ yang memiliki status gizi normal, 1 responden $(8,33 \%)$ memliki status gizi kurus.

Berdasarkan hasil analisa diketahui nilai $\mathrm{P}$ value sebesar $0,015<0,05$ sehingga dinyatakan ada hubungan Status gizi dengan Kejadian dismenorea.

Jika seorang anak perempuan kedatangan menstruasi pertama untuk pertama kali, hal ini bisa menjadi saat yang mengecewakan baginya. Anak-anak perempuan yang tidak mengenal tubuh dan proses reproduksi mereka, bisa mengira bahwa menstruasi merupakan bukti adanya penyakit atau hukuman akan tingkah laku yang buruk. Anak-anak perempuan yang tidak diajari untuk menganggap menstruasi sebagai fungsi tubuh normal akan merasa malu dan merasa kotor saat menstruasi pertama mereka. Bahkan, saat menstruasi akhirnya dikenalinya sebagai proses yang normal, perasaan kotor bisa tinggal sampai masa dewasanya. Akan tetapi, dalam tahun-tahun belakangan ini, pendidikan anatomi dan fisiologi yang lebih baik telah menjadikan anak-anak perempuan menerima kedatangan menstruasi. (Maulana, 2009).

Meskipun demikian, banyak wanita mengalami ketidaknyamanan fisik selama beberapa hari sebelum periode menstruasi mereka datang. Kira-kira setengah dari seluruh wanita menderita dismenorea atau menstruasi yang menyakitkan. Hal ini khususnya sering terjadi di awal-awal masa dewasa. Gejala-gejala dari gangguan menstruasi dapat berupa payudara yang melunak, puting susu yang nyeri, bengkak, dan mudah tersinggung. Beberapa wanita mengalami gangguan yang cukup berat seperti kram yang disebabkan oleh kontraksi otot - otot halus rahim, sakit kepala, sakit pada bagian tengah perut, gelisah, letih, hidung tersumbat, dan ingin menangis (Maulana, 2009). Pada remaja wanita perlu mempertahankan status gizi yang baik, dengan cara mengkonsumsi makanan seimbang karena sangat dibutuhkan pada saat haid. Pada saat haid fase luteal akan terjadi peningkatan kebutuhan nutrisi. Dan bila hal ini diabaikan maka dampaknya akan terjadi keluhan-keluhan yang menimbulkan rasa ketidaknyamanan selama siklus haid (Paath, 2004).

Bagi sebagian wanita, menstruasi dapat membuat rasa cemas karena disertai rasa nyeri ketika menstruasi tiba. Kondisi ini di kenal dengan nyeri menstruasi atau dismenorea, yaitu nyeri menstruasi yang memaksa wanita untuk istirahat atau berakibat pada menurunnya kinerja dan berkurangnya aktifitas sehari-hari (bahkan, kadang bisa membuat lemas tidak berdaya) (Proverawati dan Misaroh, 2009). Hampir seluruh perempuan pasti pernah merasakan nyeri menstruasi (dismenorea) dengan berbagai tingkatan, mulai dari yang sekedar pegal-pegal di panggul dari sisi dalam hingga rasa nyeri yang luar biasa sakitnya. Umumnya nyeri yang biasa terasa di bawah perut itu terjadi pada hari pertama dan kedua menstruasi. Rasa nyeri akan berkurang setelah keluar darah yang cukup banyak (Proverawati dan Misaroh, 2009).

Status gizi yang kurang atau terbatas selain akan mempengaruhi pertumbuhan, fungsi organ tubuh, juga akan menyebabkan terganggunya fungsi reproduksi. Hal ini akan berdampak pada gangguan haid, tetapi akan membaik bila asupan nutrisinya baik. Pada remaja wanita perlu mempertahankan status gizi yang baik, dengan cara mengkonsumsi makanan seimbang karena sangat dibutuhkan pada saat haid. Pada saat haid fase luteal akan terjadi peningkatan kebutuhan nutrisi. Dan bila hal ini diabaikan maka dampaknya akan terjadi keluhan-keluhan yang menimbulkan rasa ketidaknyamanan selama siklus haid (Paath, 2004).

Menurut Kusmiran (2011) dismenorea sekunder terjadi karena ada penyakit atau kelainan yang menetap seperti infeksi rahim, kista atau polip, tumor sekitar kandungan, serta kelainan kedudukan rahim yang mengganggu organ dan jaringan di sekitarnya. Hasil penelitian juga menunjukkan bahwa sebagian besar responden dengan status gizi normal mengalami dismenorea primer sebanyak 69 responden $(68,4 \%)$ sedangkan sebagian kecil gizi gemuk juga mengalami kejadian dismenorea primer yaitu sebanyak 2 (1,9\%) responden (Kusmiran, 2011.) Berdasarkan hasil penelitian yang dilakukan Yetti (2005) didapatkan hasil 35 orang $(66,0 \%)$ mengalami dismenorea dan 18 orang $(34,0 \%)$ tidak mengalami dismenorea, 51 orang $(96,2 \%)$ status gizi normal,dan 2 orang $(3,8 \%)$ status gizi pendek. Hasil penelitian ini menunjukkan ada hubungan antara status 
gizi (indeks TB/U) dan frekuensi olahraga dengan kejadian dismenorea pada remaja putri kelas II SLTPN 12 Semarang 2005.

Menurut Andira (2010) bahwa penyebab dismenorea primer yaitu peningkatan kontraksi rahim yang dirangsang oleh prostaglandin (salah satu hormon di dalam tubuh yang menyebabkan terjadinya kontraksi pembuluh pembuluh darah dan penurunan aliran darah sehingga menyebabkan terjadinya proses iskhemia dan necrosis pada sel-sel dan jaringan. Sedangkan penyebab dismenorea sekunder yaitu endometriosis, penyakit peradangan rongga dalam daerah kemaluan, peradangan tuba fallopi, perlengketan abnormal antara organ dalam perut, pemakaian IUD (Andira, 2010).

\section{KESIMPULAN}

Berdasarkan hasil penelitian diperoleh gambaran bahwa dari 58 responden $(82,85 \%)$ yang mengalami kejadian dismenorea mayoritas status gizi kurus $(55,17 \%)$ dan 12 responden $(17,15 \%)$ yang tidak mengalami kejadian dismenorea mayoritas status gizi gemuk.

Hasil penelitian ini menunjukan nilai $P$ value sebesar $0,015<0,05$ sehingga dinyatakan Status gizi dengan Kejadian Dismenore berhubungan nyata.

\section{SARAN}

1. Perlunya peningkatan peran dari instansi terkait dalam rangka meningkatkan pelayanan kesehatan khususnya Kesehatan Reproduksi Remaja Putri di Sekolah SMPN 2 Tanjung Timur kec. STM Hulu Kabupaten Deli Serdang.

2. Diharapkan adanya penelitian lanjutan dengan pengembangan variabel yang berkaitan dengan dismenorea.

\section{DAFTAR PUSTAKA}

Anurogo,D. \& Wulandari, A. 2011. Cara Jitu Mengatasi Nyeri Haid. Yogyakarta: ANDI Yogyakarta.

Arikunto, S. 2013. Prosedur Penelitian Suatu Pendekatan Praktik. Rineka Cipta, Jakarta

Beddu, 2015. Hubungan Status Gizi Dan Usia Menarche Dengan Dismenore Primer Pada Remaja Putri. The Southeast Asian Journal of Midwifery Vol. 1, No.1, Oktober 2015, Hal: 16-21

Budiman, dan Riyanto Agus. 2013. Pengetahuandan Sikap Dalam Penelitian. Kesehatan. Jakarta: Salemba Medika

Ghozali, I. 2012. Aplikasi Analisis Multivariate dengan Program IBM SPSS. 20. Semarang: Badan Penerbit - Universitas Diponegoro.

Kartono, K Dr. 2010. Pemimpin dan Kepemimpinan. Jakarta: PT. Raja.

Komala, 2015. Hubungan Status Gizi dengan Kejadian Dismenore pada Remaja Putri di MA Unggulan PP Amanatul Ummah, Surabaya
Kusrini, Luthfi Taufiq Emha, 2009, Algoritma Data Mining, Penerbit Andi,. Yogyakarta.

Laila, 2016. Buku Pintar Menstruasi. Penerbit :Buku Baru, Jogjakarta

Latifah, M. 2008. Peranan keluarga dalam Pendidikan Karakter Anak. artikel

Lestari, 2013. Pengaruh Dismenorea Pada Remaja. Jurusan Penjaskesrek, Fakultas Olahraga dan Kesehatan. Seminar Nasional FMIPA UNDIKSHA III Tahun 2013.

Mitayani, 2012. Buku SakuI lmu Gizi. CV Trans Info Media. Djakarta.

Morgandan Carol Hamilton. 2009. Obstetri dan Ginekoligi Panduan. Praktik. Jakarta

Muttaqin,A. 2008. Buku Ajar Asuhan Keperawatan Klien Dengan Gangguan.Sistem Imunologi. Jakarta: Salemba Medika

Ningsih, 2011.Gambaran Skala Nyeri Haid Pada Usia Remaja. Jurnal Keperawatan 'Aisyiyah, Volume 2| Nomor 2| Desember 2015

Notoadmodjo, S. 2012. Metodologi Penelitian Kesehatan. Jakarta: Pt Rineka Cipta

Novia, 2008 Faktor Risiko yang Mempengaruhi Kejadian Dismenore Primer. The Indonesian Journal of Public Health, Vol. 4, No. 2, Maret 2008: 96-104

Nugroho, T. 2010. Kesehatan Wanita, Gender dan Permasalahannya. Jogjakarta: Nuha Medika.

Parke, R. D, \& Gauvain, M. 2009. Child psychology a contemporary viewpoint. 7th. New York : Mc Graw-Hill

Pinem,S. 2009. Kesehatan Reproduksi Dan Kontrasepsi. Jakarta: Trans Info Media.

Prasetyo, 2015. Hubungan Status Gizi Dengan Kejadian Dismenore Pada Wanita Usia Subur. Fak. Kedokteran. Universitas Sebelas Maret

Prawirohardjo, S. 2006, Pelayanan Kesehatan Maternal dan Neonatal, Jakarta: Yayasan Bina Pustaka

Proverawati,A., dan Misaroh, S. 2009. Menarche Menstruasi Pertama Penuh Makna.Yogyakarta: Nuha Medika.

Purwanti, 2014. Faktor - Faktor Yang Berhubungan Dengan Kejadian Dismenore Pada Siswi Kelas $X$ di SMK NU Ungaran

Rahmadhayanti, 2016. Hubungan Status Gizi Dan Usia Menarche Dengan Dismenorhea Primer Pada Remaja Putri Kelas Xi SMA Negeri 15 Palembang. Jurnal Kesehatan, Volume VII, Nomor 2, Agustus 2016, hlm 255-259

Riyanto, 2011. Buku Ajar Metodologi Penelitian. Jakarta: EGC

Saryono, 2009. Sindrom Premenstruasi. Nuha Medika. Yogjakarta.

Sarwono.S.W. 2011. Psikologi Remaja. Jakarta: PT Raja Grafindo Persada

Schorge et al. 2008 .Menopause dalam Williams Gynecology edisi 23. New York: The McGrawHill Companies. 
Sophia, 2013. Faktor - Faktor yang Berhubungan dengan Dismenore pada Siswi SMK Negeri 10 Medan Tahun 2013

Sugiyono.2010. Metode Penelitian Kuantitatif Kualitatif\& $R N D$. Bandung :Alfabeta.

Tarwoto.2010. Kebutuhan Dasar manusia dan Proses Keperawatan. Jakarta. Salemba Medika.

Utami, 2013. Faktor Yang Berhubungan dengan Kejadian Dismenorea Pada Remaja Putri di SMAN 1 Kahu Kabupaten Bone. Fakultas Kesehatan Masyarakat, UNHAS, Makassar. FKM USU
Yustiana .2011. Hubungan Status Gizi Dengan Keluhan Nyeri (Dismenore) Saat Menstruasi Pertama (Menarche) Pada Siswa SLTP Di Surakarta. Universitas Sebelas Maret:

Waryana, 2010. Gizi Reproduksi .Putaka Rihama, Yogjakarta 